express, or the Royal prerogative can direct, that there shall be four grades in the medical officers of H. M.'s Indian military forces; and you and every other man whose eye is single must see that the grades of inspector-general and of deputy inspectorgeneral are superior to and extra of the rank of surgeon ; and Paragraph 7 lays down the obligation on the execntive so to promote, and confers the right on the service to be so promoted; and if the statement of the "equal footing" is truth, Mr. Bazley, the Parliament of Great Britain, and the profession at home, must believe that promotions have been made in tho Indian service in like manner as they have been made in the British Army.

But how stands the case? From the date of the promulgation of the Warrant to the service till this day, when a deputy inspector has been made inspector, or when a surgeon has been made deputy inspector, there has never once been a promotion made in the Indian service, in time and in degree, as occurs in the British service. On neither of these occasions has a vacancy taken place in the grade of surgeon. The inspectors and deputy inspectors have, contrary to right and privilege conferred, and to current usage, been retained on the list of surgeons, to the prejudice, absolute or contingent, of every assistant-surgeon in the Army. The consequences of this infringe. ment of the Royal Warrant in In tia have been-

lst. That the inspectors and deputy inspectors are merely surgeons doing the duty of those grades, they being still retained in the regulated number of surgeons.

2nd. That a number of assietant-surgeons, who ought to have been promoted to the surgeoneies previously filled by the above (and as obtains in the British Army), have not been so pro. moted, and are thereby, in violation of the letter of the Warrant, kept out of their lawfinl rights and privileges, and defrauded of the rank, pay, and allowances of surgeons, and some of these gentlemen have been assistant-surgeons of nineteen (!) years' standing.

Is must therefore be perfectly evident to you that in this point of view it is not true that both services have been placed on an " equal footing." The British Medical Service gets the promotions, pay, and allowances contemplated in their War. rant; whilst the Indian Medical Service is unlawfully kept ont of them.

Take the case of furlough pay. A British medical officer goes home on sick leave, and he gets the proper pay of his rank, as laid down in her Majesty's Warrant. The Indian medical officer (unless alterations have been made which are unknown in India) gets much inferior pay in similar circum. stances; for if a surgeon, he merely gets the old pay of captain and if an assistant-surgeon of eighteen years' standing, he only gets the old pay of lieutenant. While the Queen's surgeon, who probably did not enter the army till the latter had been an assistant-surgeon for ten years, is paid as his Warrant provides, the other is not treated according to the commonest equity. Surely this is not an equal footing!

You have already published the Bombay Nedical Memorial, I believe, so I shall not take up your space to demonstrate that neither in the matter of "pensions after fixed periods of service," nor in that of "good service pensions," are the services on an equal footing. Mr. Bazley has evidently got an inkling that something is "rotten in the state of Denmark." This is not the first time that he has in his place in Parliament received unsound and untrustworthy information from the Secre. tary for India. The Indian Medical Service was inexpressibly astounded to see in the Overland Mail that, on the 16th of March, 1561, he had, in answer to a question he had put to Sir C. Wood, as to whether "all the privileges-riz, rank, pay, and pensions conferred by the Royal Warrant of $185 \mathrm{~s}$, had been conceded to her Majesty's Indian Army," been told by Sir C. Wood that "the rank, pay, and position of the Indian medical officers and British medical officers in India had been put on a footing of perfect equality."

Sir, I can assure Mr. Bazley that when this statement, made in reply to his question, reached India in the April following, medical officers looked at each other in astonishment; for with the facts before their eyes-that no medical warrant had been published in India; that no assistant-surgeons of six years' standing had been promoted to the rank of captain, nor surgeons to that of surgeon-major, \&c, - they were astounded and feeling the statement to be unqualifiedly inconsistent with fact and truth, they could not possibly guess what Sir Charles Wood meant.

I would beg to commend to Mr. Bazley's perusal the Bombay Medical Memorial-it is correct, acrurate, and true, and worthy of his confidence; while, if Sir C. Wood's reply to his recent question, as reported in the Overland Mail, is substantially correct, and the statements $I$ have made are true (and I refer you to any Indian medical officer now at home for verification), it must be painfully evident to him that. as statements of fact, the information he has twice received in the House of Commons is not only worthless in the highest degree, but a sad exemplification of mischievous ignorance and reckless assertion. We do not suppose that the Secretary for India would wilfully misrepresent the condition of a service of which he is the ap. pointed guardian; but his duty to her Majesty, to Parliament, and I will even say to the service itself, renders it necessary for him to be correctly informed regarding it. Possibly, some clerk in the India Office-a Mr. Smith or a Mr. Jones - takes charge of the Indian medical service, and perhaps, on his way to Camberwell of an afternoon after office hours, he arranges the reply to be made by his chef to an awkward question in the House; but he might recollect that there are limits beyond which it is not prudent to go.

You, Sir, have ever done as much as you could for the India service in the colomns of your journal; and, as a brother medico lately remarked to me when discussing our grievances, "THE: LANCEm often gives us the help of an editorial." I trust you will not drop the agitation till the service receives its due meed of justice, for here, it is sad to say, hope is sunk in a Dead Sea of stagnation; and the mismanagement of one who ought to have been its guardian and protector has so soured and em. bittered the service, that his name is never alluded to, where one or two members meet, but with a peculiar sense of injustice and an energy of dislike.

Deccan, Septemiver, 1861 . I am, Sir, yours faithfully,

INDICUs.

ON THE

\section{EMPLOYMENT OF QUININE IN FEVERS AND OTHER DISEASES.}

\section{To the Ellitor of THE LANCET.}

SIR,-The discussion on Dr. Livingstone's supposed noveI treatment of tropical remittent fever, reported in your journal of August 24th, affords an apt illustration of the ill-effects resulting from the way in which the recorded experience of our medical officers has hither to been allowed to monlder on official shelves. That gentleman's success, I have no doubt, is due, not to any combination of common purgatives, as appeared to be supposed, but to the administration of quinine in the very outset of fever. The doctrine of the schools, which teaches us that we dare not give quinine in such cases till a distinct remission is established, and that a hot skin with dry rough tongue \&c. altogether forbid its administration, has, I firmly believe, cost the lives of thousands. I saw a frigate, fresh from England, lose so many of her crew from this disease, though treated on shore, that she was ordered to sea, as the only means of shaking off what was termed a "malignant fever;" while the garrison of the station, prostrated by the disease, lost only one man, a notorious druukard. It was certainly a very unhealthy season, for there was hardly a family in the native town that had not a death to mourn, although they had the benefit of those indigenous doctors whose skill, Lord Ellen. borough lately told the House of Lords, was so transcendently superior to that of European practitioners in India! The frigate's people were under a venerable old surgeon, who bled, purged, sweated, and salivated them, more majorum. The native doctors drenched their patients with decoctions of all kinds, purged them smartly, rubbed them with oils, and lost them, one after another, with coma. The garrison were treated with quinine and James's powder, a scruple of each, given in divided doses during twenty-four hours, beginning on admission, without any regard to burning skin, splitting headache, \&c., but with proper attention to the bowels, leeches and blisters to the head (if indicated by the persistence of cerebral symptoms), and whatever else was necessary to aid the essential remedy.

Subsequent experience (for I am now speaking of nearly twenty years ago, since which I have treated some thousands of cases) led to the omission of the antimonial, and the giving of five grains of quinine with a purgative on admission, repeating the former twice, at intervals of two buurs, in all serious-looking cases. I may say that I, almost accidentally, stumbled on the art of using quinine in tropical diseases, in the year 1836, when serving in Ceylon, at which time neither I nor anybody else there had any idea of using it, as above de. scribed, in fever, but reserved it to be given cautiously, in one- or two-grain doses, at the end of the day. The system then was that under which the frigate lost her crew, and speedy 
salivation was the object aimed at. The new plan had many prejudices to contend against; and I remember seeing an officer delirious, and far gone in fever, to whom his attendant posi. tively refused to give quinine, notwichstanding all that could be urged, and the admission of his extreme danger. Fortuaately for the patient, I was the recusant's superior officer, and, for the only time in my life, enforeed my prescription by military authority, so that I had double satisfaction in seeing the delirium subside and the desired remission take place under the infiuence of the remedy. For many years past the practice has been universal in Ceylon, and, no doubt, in many other quarters also. I found it perfectly successful during the second summer of the Bengal mutiny, when we had hundreds of cases on the banks of the Ganges, and the mortality from fever in some corps was excessive. The mode of treatment was, of course, regularly reported, year by year, to the DirectorGeneral; and, in 1849, Sir James $\mathrm{M}^{6}$ Grigor communicated to the Edinburgh Quarterly a special report on the subject which I addressed to him. Since those days, and in the course of an extensive practice, civil as well as military, I have become convinced that quinine is the master key to the treatment of nearly every tropical disease, in nearly all of which attention, once directed to the point, will rarely fail to detect a periodic typethat is, a distinctly recurring exacerbation of symptoms, but notinecessarily involving increased heat or rise of pulse. Thus in dysentery, the most dreaded disease of the tropics, a patient will have a rapid succession of bloody stools, with aggravation of tenesmus, and great prostration, at some certain period of the twenty-four hours; and, in such cases, one or two tengrain doses of quinine, given in the interval, will often ward off the attack, just as it would that of ague, and usher in recovery.

The malarious type of dysentery is one of its most fatal forms, and should be regarded, in a great measure, as essentially fever, with disease of the bowels superadded, though unfortunately the urgency of the local symptoms too generally occupies th whole attention of the physician. This is the form of the dis ease constantly seen in woody, marshy countries like Ceylon and which, asthenic in itself, becomes deadly if treated, merely for its name, by the usual routine of aperients, leeches, calomeland-opium, particularly when it appears amongst a body of men weakened, as soldiers so often are, by constant solar exposure, night duties, and want of proper nourishing food. In such cases, after a dose of oil, quinine should be given to the extent of twenty or thirty grains in twenty-four hours, with as much ipecacuanha as the stomach can be got to bear, aided by opiates, astringents, counter-irritation, and plenty of nourishment suitable to the disease. The acute capillary bronchitis, which, treated on the old system, used to cause great mortality amongst infants and young children in those countries, is in like manner essentially fever, and its most alarming symptoms, when the tubes are stuffed with mucus, and the child half asphyxiated, will often subside with astonishing rapidity after a smart emetic, followed by frequently repeated doses of qui nine, combined, if it can be done, with ipecacuanha or James's powder. The youngest infants can take with benefit from two to five grains of quinine in twenty-four hours, and in their case this mode of treating fever is a particularly great improvement, as the dosing such little creatures with calomel, antimony, \&c. on the old system was most distressing to all parties concerned, and too frequently ended in death. Few people have any idea of the fearful amount of mortality amongst the children of our soldiery in the tropics, particularly in regiments not blessed with a kind-hearted, patient assistant-surgeon, who will take pity on the neglected women and children, and devote some attention to the little folks' ailments. Nor do I beliere that the powers of quinine to overcome such (apparently) acute forms of disease are at all limited to the tropics. During the last three years I have used it very freely in the same way in England, and often with rapid relief to the patient, particularly in catarrhal and bronchitic affections during the last severe winter.

When one reflects on the vast number of valuable reports which have necessarily been furnished to the respective medical boards, embodying the experience and knowledge acquired by thousands of educated men in all corners of the globe, it is clear that a separate bureau for practical medicine ought long ago to have formed a special department of each office. At its head should be an able officer, charged to keep the scattered members of the corps acquainted with all discoveries and im. provements in their art, and to digest and publish for general information the detailed observations on climate, topography, disease, and its treatment, which are furnished from our im. mense possessions. To do this effectually and permanently, he would require to send forth, not a tardy volume, like the recent "Army Medical Reports," dealing in crude generalities, through which readers must wade to conclusions, and containing flimsy "Annual Reports," which it would be a libel on the Department to consider the best specimens furnished amongst several hundreds; not a ponderous tome of this sort, but a military medical journal, a regular bi-monthly or quarterly periodical, the very establishment of which would call forth a general esprit-de-corps, and induce many of its ready-made body of subscribers to become frequent contributors. With this there should be given at stated periods, say of three or five years, an analytical retrospect of the advances made and results established in its pages during each interval. In this way we should have always available an immense body of information on all countries and climates, now scattered and buried, no one knows where. We should also see established on the sure foundation, not of clever theory, but of successful practice, a definite system of treating climatorial diseases; so that when a young officer landed in one of our colonies he would be enabled to begin where his most experienced predecessors left off, in stead of being left, as now, either to grope his way to their conclusions at a great waste of human life and suffering, or perhaps never to reach them at all.

I am, Sir, your obedient servant,

J. C. Cameron, M.D., Deputy Inspector-General, Nottingham-place, October, 1861.

\section{THE REDUCTION OF STRANGULATED HERNIA. \\ To the Editor of THE LANCET.}

SIR, - - In your journal of October 26 th I notice a communication from Mr. Fugg, alluding to the paper I published in October, 1860, on the Method of Reducing Strangulated Hernia by Raising the Pelvis, \&c. If that gentleman will favour me by turning to The LANCET of Dec. 15th, 1860, he will find that I quote the curious paragraph in question, and refer to it as supplied to me by Dr. Wilson, of this town, who happened at the time to be reading the life of Lord Dundonaid.

In noticing this last communication on the subject, I trust that I may be permitted to remark on the numerous successful cases which have been published in the various serials, and to the sanction which has been given to the practice by some of the first surgical authorities of the day. Mr. Bowman, of King's College, and Mr. Power, of the Westminster Hospital, have both adopted the practice successfully; and Mr. Pound of Odiham, has lately, in conjunction with Dr. Hall, published an exceedingly important case in point. The subject is certainly one of interest, and I beg your permission to record in your pages the accompanying communication, received a few weeks since from Melbourne. I should observe that Mr. Gillbee has made a slight error in the date of the publication of my paper.

"Melbourne, July 25th, 1861.

"Drar Str,-Having read in The Lancet of Nov. 17 th, 1860, your paper upon Strangulated Hernia, and having availed myself of your valuable suggestions with success, and which has been published in the Australian Medical Journal, I have taken the liberty of enclosing a slip containing the case, thinking you may feel interested in the success of your line of treat. ment even at the antipodes.

$$
\text { "W. Jessop, Esq." " "Surgeon to the Melbourne Hospital, Vietoria. }
$$

"On the 13th of May last, I was called in to visit Mr. $\mathrm{R}-$, of Colling wood, whom I found suffering from strangulated hernia. He is a man of forty-five years of age, and of spare habit. He stated that he had suffered from inguinal hernia of the left side for the last twelve years, which he had always been able to return, and for which he had not worn a truss until the last three weeks. That on Sunday morning, about two A.M., the hernia came down, and he was unable to reduce it as usual. That at six A.M. great pain ensued, and vomiting set in, which symptoms continued to increase, and for the relief of which he took castor oil, and had fomentations, being reluctant to call in medical assistance. The symptoms, however, became so alarming that I was sent for on Monday evening. Forty-three hours after the strangulation had occurred, I found him suffering intense pain over the whole of the abdominal region. There were hiccough, stercoraceous vomiting, and great prostration, almost amounting to collapse. The hernia was about the size of an ordinary egg, and extremely tense. I endeavoured to reduce it by careful manipulation, 